\title{
A MICRO-CONTROLLER BASED AUTOMATED PRODUCT DISPENSER
}

\author{
${ }^{* 1}$ Mr. Sarath Kumar R, ${ }^{2}$ Aravind M, ${ }^{3}$ Dayanand B, ${ }^{4}$ Devarajan S, \\ ${ }^{\mathbf{5}}$ Aswith S, ${ }^{6}$ Luis Cruz Govindapillai \\ ${ }^{*}$ Assistant Professor, Department of ECE Sri Krishna College of Engineering and \\ Technology Coimbatore, India \\ 2,3,4,5,6 Department of ECE Sri Krishna College of Engineering and Technology Coimbatore, \\ India \\ ${ }^{* 1}$ Email: sarathkumarr905@gmail.com
}

\begin{abstract}
The Objective of the paper is to make a "Product dispenser" as an outcome which is very helpful in reducing unnecessary wastage of product and to avoid physical contact during this pandemic situation. (e.g.: water, any liquid items). So, a product we have chosen is "liquid such as water, juices, cold drinks, canned, etc....". Nowadays the product dispenser system is like a regular vending machine. So, it is used in our day-to-day daily life as an easement. These vending machines are mostly available in public places like shopping mall, Metro, Airports, Hotels, etc... Hence, it is a convenience for people to use. But, in the pandemic Situation, the safety of the people comes first. So, in order to prevent many people from physical contact with the dispenser machines, we came up with an idea of examining the body temperature and then proceeding to the next dispensing section. By, this method we can ensure the safety of the people from being exposed to viruses at the maximum.
\end{abstract}

Keywords: Temperature check, Automation, Product dispenser, Avoid Physical contact, Save Resources.

\section{INTRODUCTION}

A vending machine is an automated machine that sells various things when we insert a coin. It can offer many things like sandwiches, chips such as potato, chocolate bars, cigarettes, and beverages such as hot drinks, cold drinks, or newspapers. The first contemporary coin based vending machines, which dispensed postcards, were launched in London UK, in the early 1880s. Percival Everitt was the first man to create the machine in and show to public in 1883, and it was used to distribute postcards and notepaper in railway stations and post offices.

"Dispenser" means an element or some product/things is letting out. Here we use the name product dispenser, letting out only the necessary product and saving the remaining to avoid getting wasted. So, product we have chosen is "liquid such as water, juices, cold drinks, canned, etc....". The main theme of doing this paper is to save products (liquid such as water, juices, cold drinks, canned, etc....) use it for only necessary purposes and to check the consumers temperature before coming into contact with the dispenser. So, we should take 
care and use it for necessary purposes. So, to save guard our food products. we took a small measure to so a paper called "Product dispenser" with the theme of checking the consumers body temperature. Thus, minimizing risk of getting affect with diseases during, the contact with dispensers.

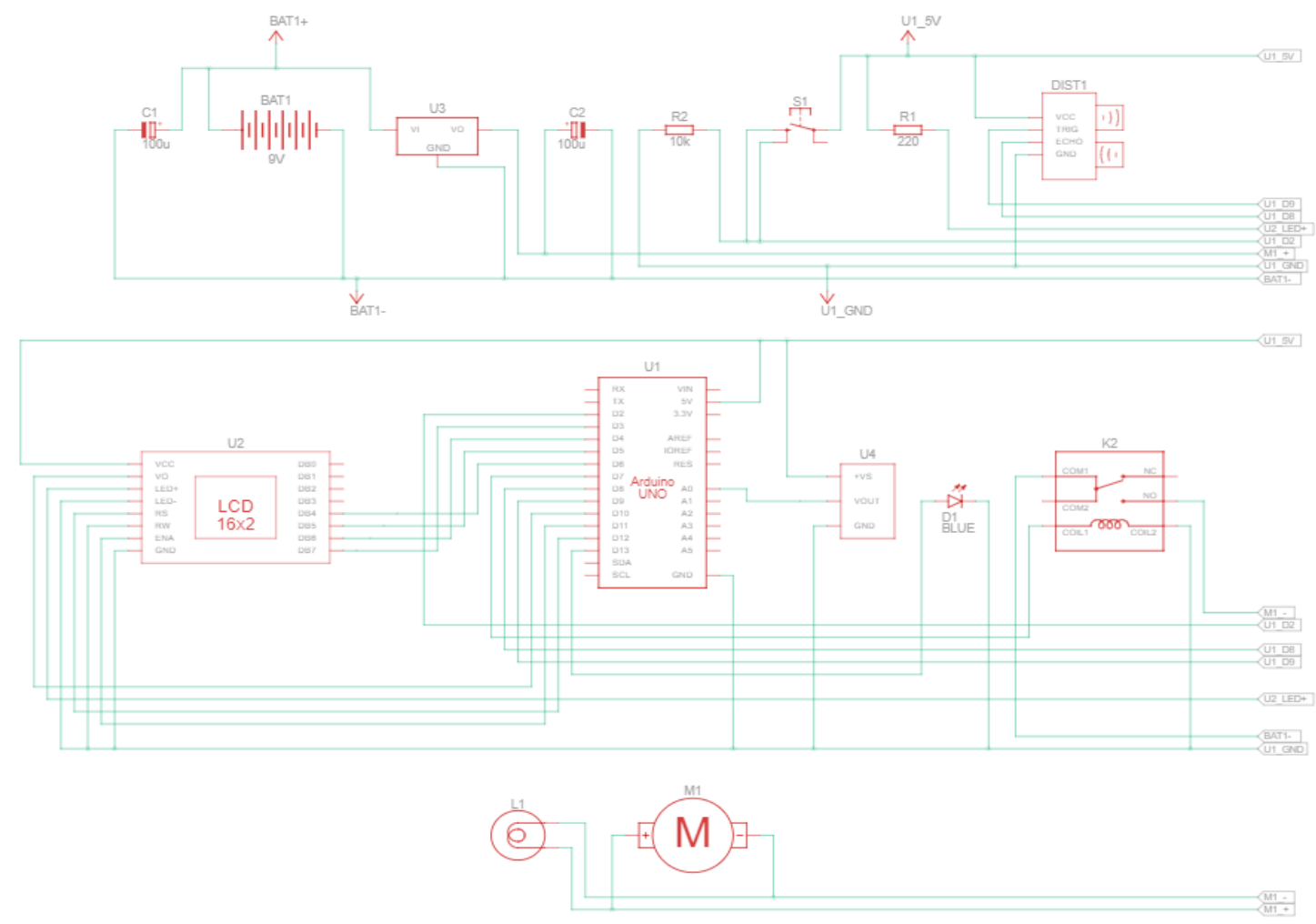

Fig. 1: Schematic Diagram

\section{EXISTING SYSTEM}

In the previous coin based vending machine either the microcontroller or processor is utilized for the entire interaction and their coding is likewise muddled. This may likewise use to detect the lodging of coin through the cash bay and furthermore faculties how much item to be conveyed precisely by the electrical motor. When the phony coin with same consistency and same size lodging to the coin lodge area the coin can be acknowledged and the items can be conveyed without detecting the coins, this might be considered as the significant downside of this current machine. And Another disadvantage is that owing to inadequate balance in the vending machine, the balance amount of coin cannot be collected. There is also the possibility that older coins will not be accepted due to the systems in place.

In the existing dispenser we will have a button kind of system. As a result, if a person with a virus or sickness uses the product dispenser, he or she may come into direct contact with the dispenser. This physical touch will also influence another individual who is using the same dispenser. To counteract this, our Automated Product Dispenser will prevent the spread of certain illnesses. 


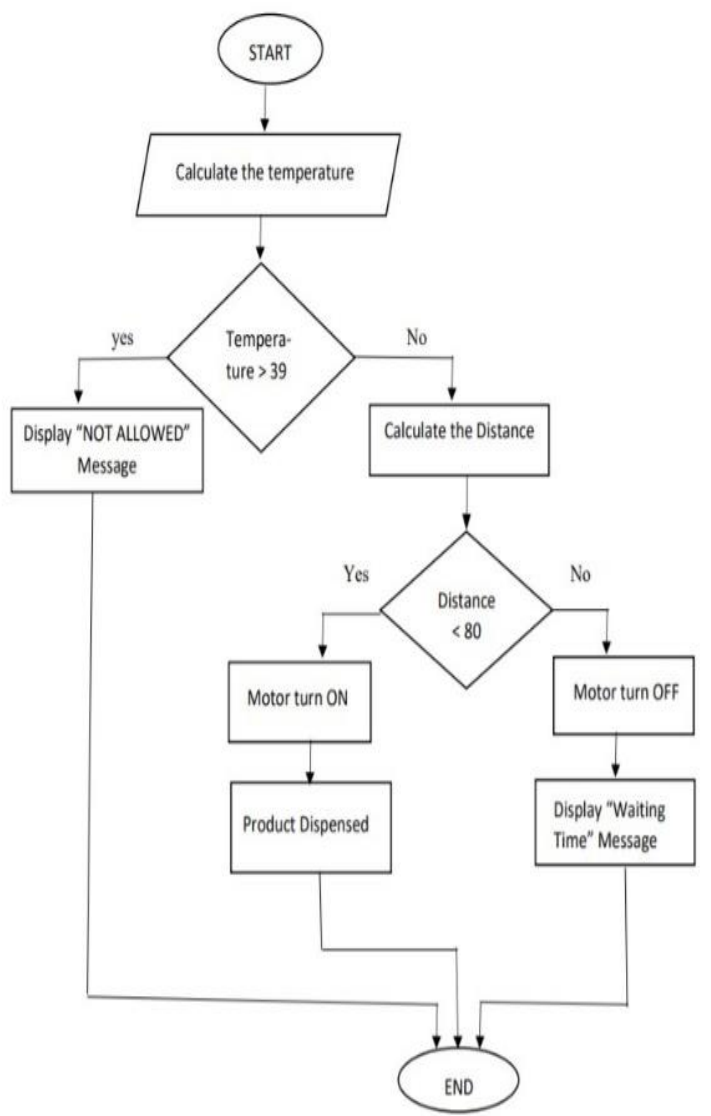

Fig. 2: Flow chart

\section{PROPOSED SYSTEM}

In our proposed system, we have used Arduino UNO as the microcontroller because Arduino software is open source and it supports lots of micro-controller chips like ARM and AVR and it also has serial communication ports. The Coding language for Arduino is Embedded C which is quite similar to $\mathrm{C}$ language and it is easy to use and code our system. So, automation will become quite easy with the help of Embedded C.

In this paper, we have introduced a new idea, which will be useful for this pandemic situation and also in the upcoming days. Here, we have added an additional section for determining the body temperature of the consumer and then allowed to use the dispensing section. At, the first before using the machine, the user is made to check their body temperature, which is done automatically using the temperature sensor. Here, when the user shows their hands, the sensor automatically senses and then decides whether the user can be allowed to proceed to further process. In the event that the user's body temperature is anomalous, at that point a caution message is sent to the closer hospital. Then after the temperature checking part is over, the next section of dispensing is activated. In the dispensing section the liquid products such as coffee, tea, juices, soda, etc.... are already stored in their respective containers. When the user keeps the cup/glasses (which is kept nearby in a stand), under the respective products, the sensor will sense and on the solenoid value/motors for outlet of liquid products, and then fill the glass. The time to fill the glass is already given in the coding section. In addition to this 
when the user suddenly takes out the glass/cup, by the help of sensors/button it is made to stop. So, the wastage of the products is reduced. This method can also be used in homes, acting as an Automatic water dispenser, with the help of temperature sensor. So, whenever the people come from outside places, they need to check their body temperature and then allowed to drink the water. By, using this method there is no need for any physical contact with the machine buttons or it doesn't require any manual work filling the products into the glasses. In this method the safety is ensured for both the customers and food products.

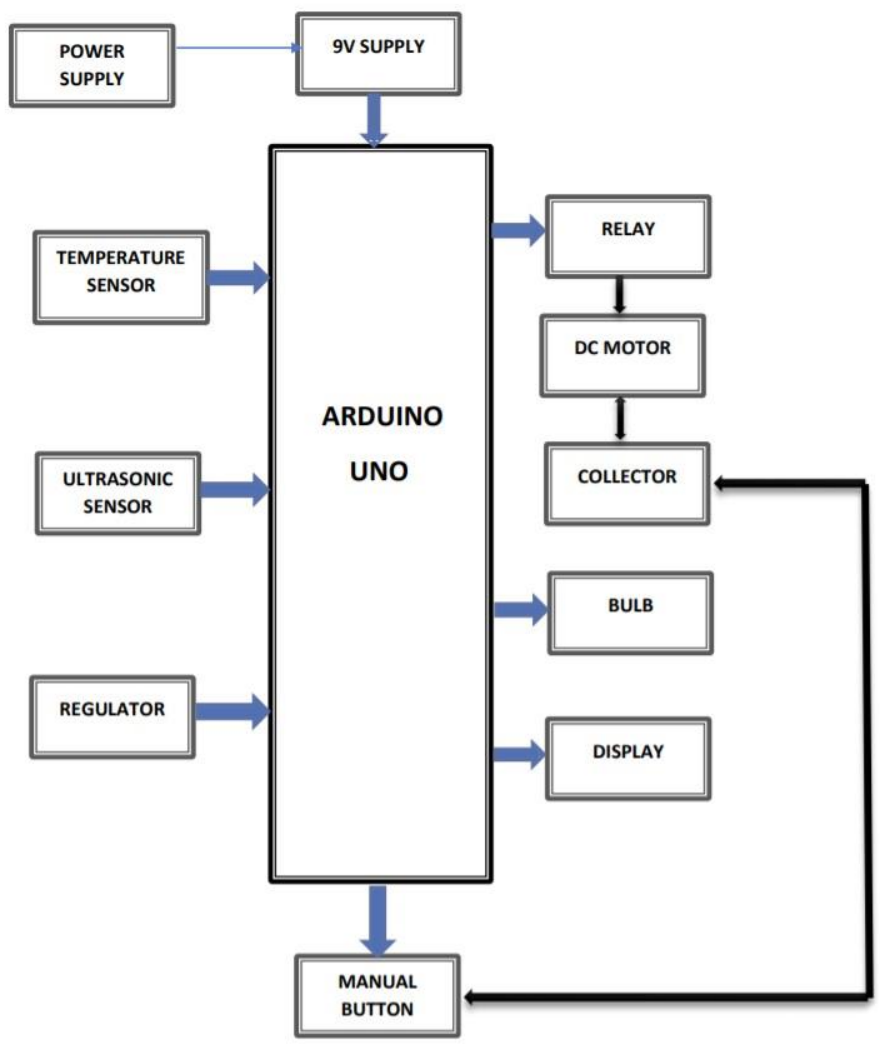

Fig. 3: Block Diagram

\section{HARDWARE PHOTOGRAPHY}

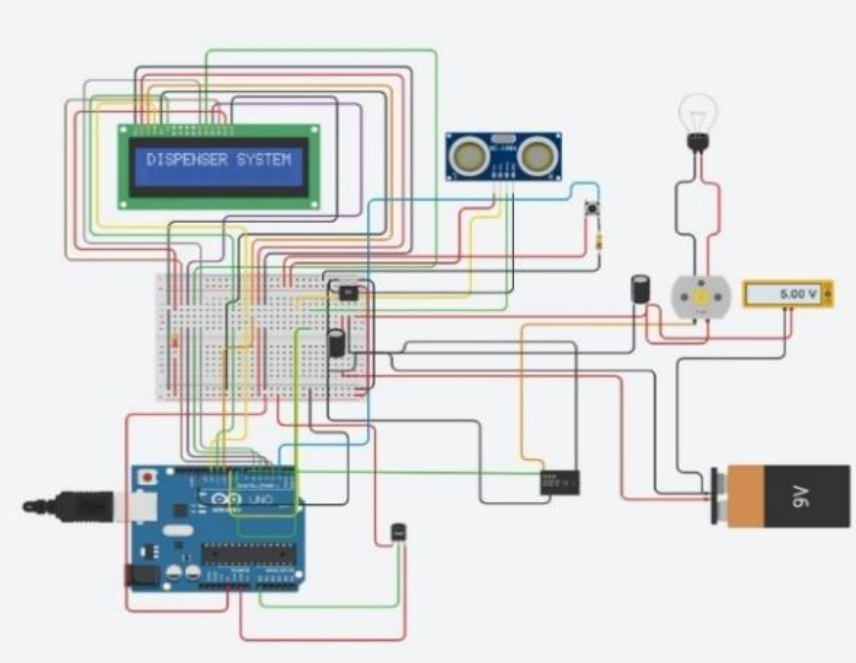

Fig. 4: Circuit diagram of product dispenser 


\section{OUTPUT}

Here, we have attached the output of our paper. At the beginning of the process display will show "Product Dispenser Ready", the system will be at on / ready state. This shows that the users can come and use the dispenser.

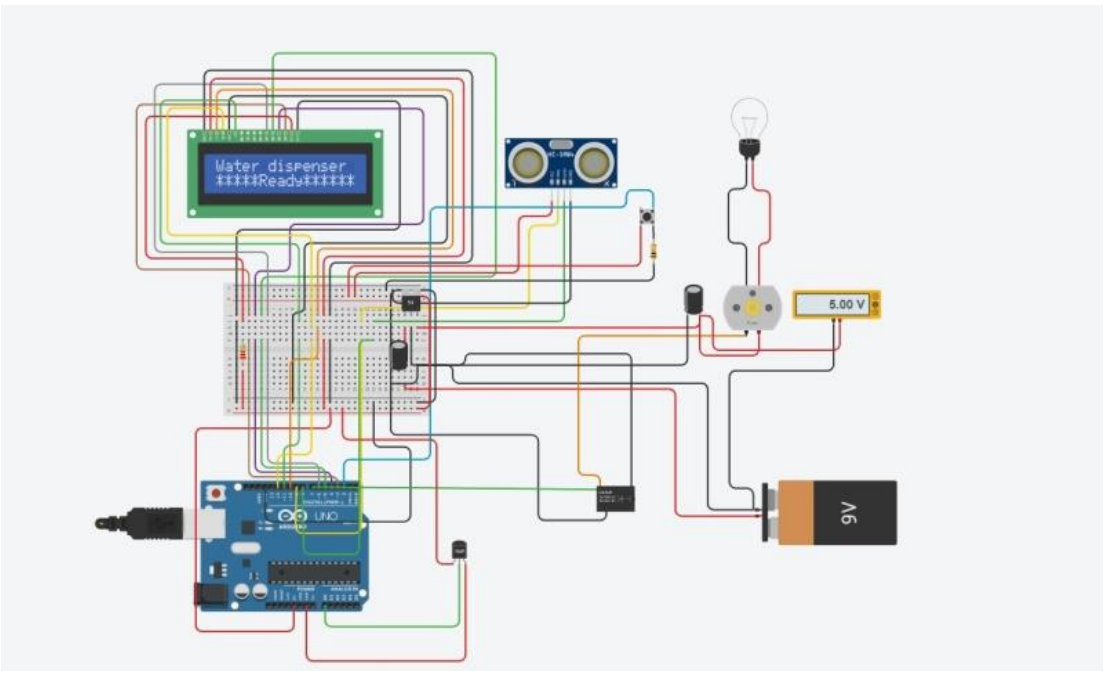

Fig. 5: Product dispenser ready

When the dispenser shows "Product Dispenser Busy", then the system is having too many process executing at the same time. This happens only when there's frequent distractions / inputs are provided by the user.

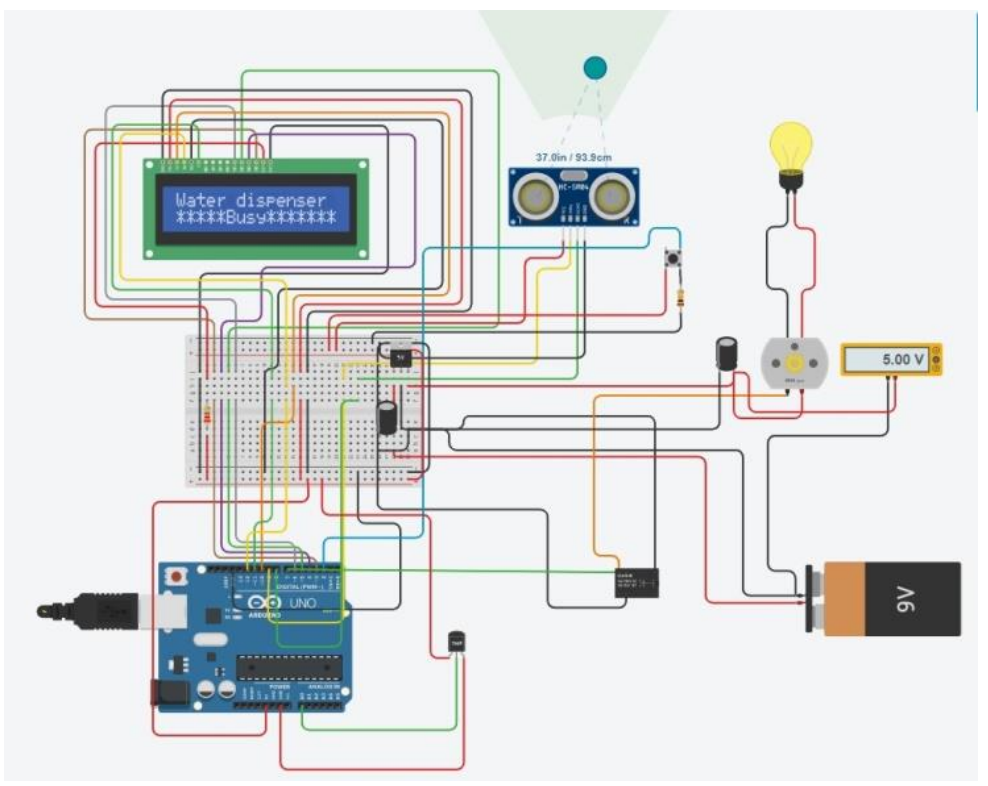

Fig. 6: Product dispenser Busy

When the glasses are filled with products like water, juice, etc. the display will show the message as "Please Remove Glass" and letting the user to know they are ready to take the out. 


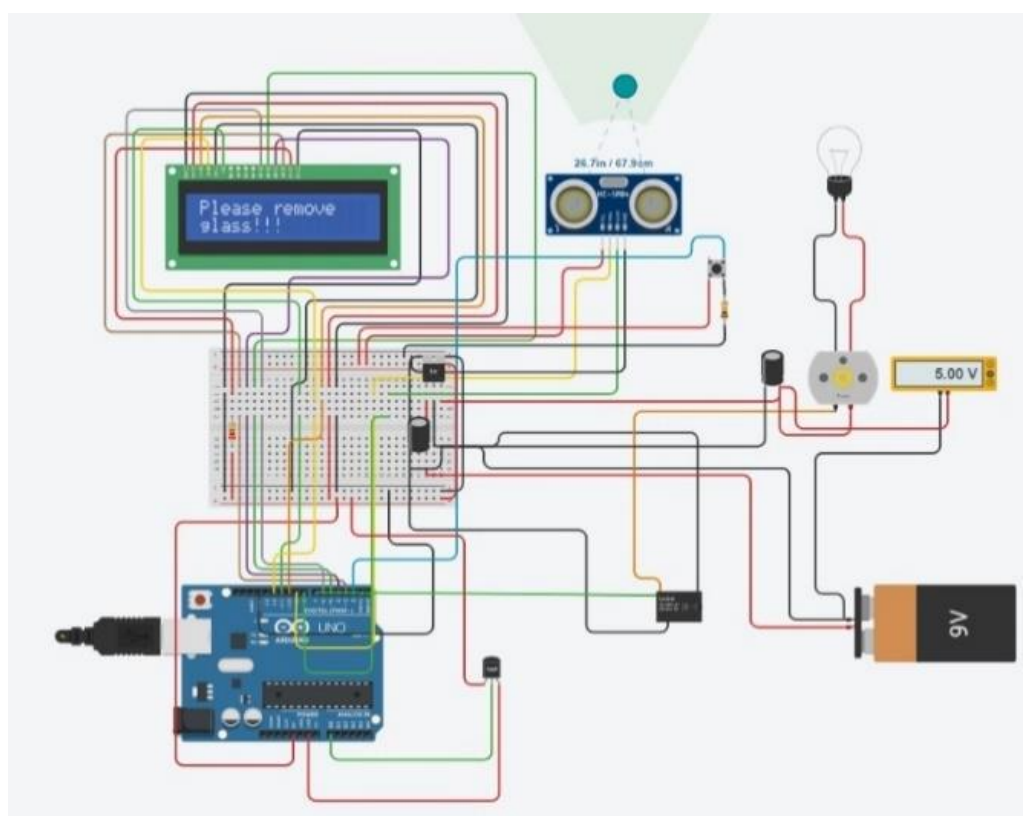

Fig. 7: Take away the glass

When the temperature of the person is abnormal, the system will display the message as "Not Allowed". Hence, the user having illness is detected and will be restricted from using the dispenser.

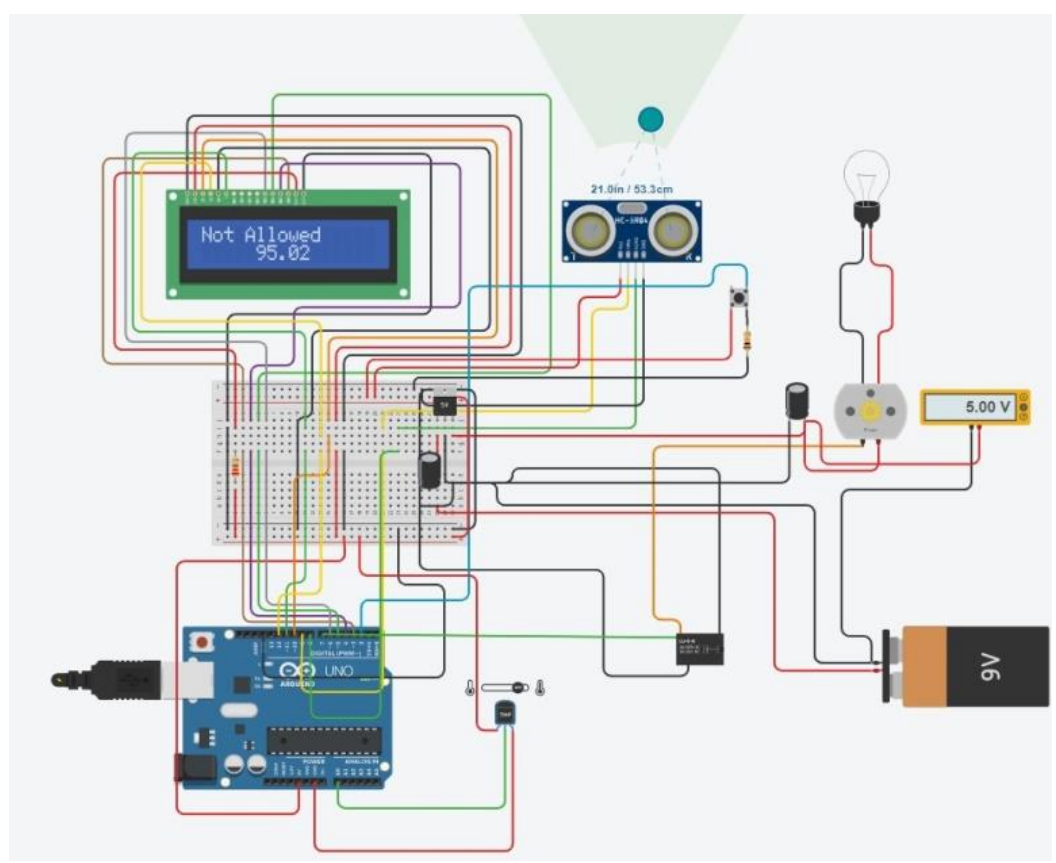

Fig. 8: Not allowed

When the person wants to start from the first / or gets any malfunction, they can interrupt the system and restart the process. It will be indicated as "Interupted". 


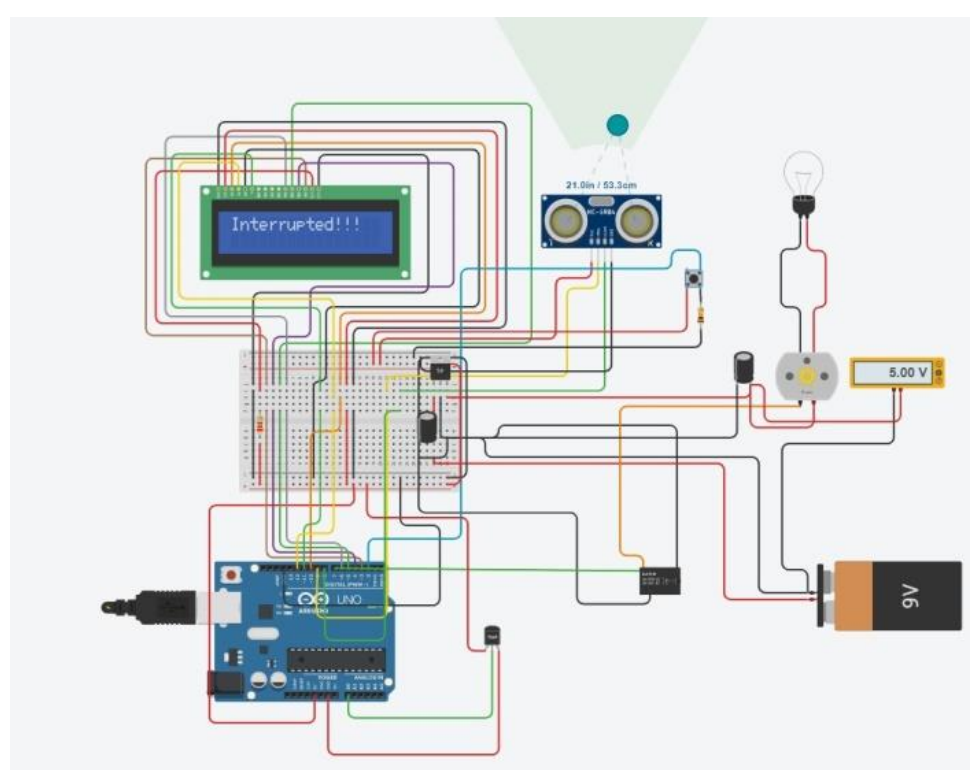

Fig. 9: Interruption

\section{RESULT}

The system is used by the Arduino to automatic the process of water which is used by us in our day-to-day life and it has the ability to detect the water level, and an LCD in this system provides the output which is very useful for us. Therefore, the expected outcome of saving the water is realized by implementing this method. It involves a simple and cost-efficient way. Through this method we can get a good quality of water and there will be no more wastage of water. So, after determining the temperature of the consumer, they are allowed to get the products from the dispenser. In that way this machine provides the safety precautions. So, without any fear we can have the drink.

This machine can be kept in any public places like cinema theaters, malls, marriage halls, etc.... by providing the various type of juice items and also for drinking water too. And also, in private places like house we can keep this machine for drinking water and any other purposes.

\subsection{Outcome}

The temperature sensor measures the person's body temperature, while the ultrasonic sensor measures the distance and sends the information to the Arduino. Then, the dc motor circuit then takes power from the Arduino and begins to revolve the spiral ring linked to it in an anticlockwise orientation. At last, the product is given to the consumer, and the limit switch can be used to halt the rotation. (The associated limit switch can be actuated by the ring after the product has been dispensed.) At the end, the motor comes to a halt. If the product is clogged or if a mistake occurs, the physical button can be used to correct it.

\subsection{Future Enhancements}

In future this system can be provided with the following specifications,

They are:

- To check the quality and expiry date of the product.

- The level of water inside the container can be measured. 
- The readings and errors can be sent to the user's mobile as a message.

- 4. To convey numerous items in a single dispenser.

\section{CONCLUSION}

During the period of pandemic doctors advised not to have social contact with each other's. So, by having that in mind we done a paper based on automation. This machine will first analyze the consumer's temperature and allows the system provide the necessary items so that the items which is provided by the machine will also be hygienic. So, the person who are using this machine will not have any physical contact with others. At every moment, the automatic product vending machine dispenses a variety of products. The gadget may be used in retail malls, airports, and businesses in today's digital age. This machine efficiently lowers the customer's time in his or her busy schedule. This system is small, cost-effective, and uses less energy, allowing it to be utilized everywhere.

\section{REFERENCES}

[1]. https://www.newair.com/blogs/learn/wate r-dispenser-basics

[2]. https://www.researchtrend.net/ijet/pdf/21-S-803.pdf

[3]. Golin, A. P., Choi, D., \& Ghahary, A. "Hand Sanitizers: A Review of Ingredients, Mechanisms of Action, Modes of Delivery, and Efficacy Against Coronaviruses". American Journal of Infection Control ,2020.

[4]. Perumal T. M.N.; Mustapha, N.; Shahi, A.; Thinaharan, R., "Proactive architecture for Internet of Things management in Home automation," Consumer Electronics, 2015 IEEE 3rd Global Conference on, pp.16,17, 7-10 Oct. 2017.

[5]. "Smart Home Automation Based on IOT Technologies," Computational and Information Sciences (ICCIS), $20135^{\text {th }}$ International Conference on, pp.1789,1791, 21- 23 July 2012.

[6]. Senior, Dorothy (2011). Dege, Nicholas (ed.). Technology of Bottled Water (3rd ed.). Chichester, UK: Blackwell Publishing Ltd. p. 8. ISBN 978-1-4051-9932-2.

[7]. Reid, Robert (2004). Water Quality and Systems: A Guide for Facility Managers (2nd ed.). Georgia, USA: The Fairmont Press. p. 187. ISBN 0-88173-332-6.

[8]. Senior, Dorothy (2011). Dege, Nicholas (ed.). Technology of Bottled Water (3rd ed.). Chichester, UK: Blackwell Publishing Ltd. p. 8. ISBN 978-1-4051-9932- 2. [11] Reid, Robert (2004). Water Quality and Systems: A Guide for Facility Managers (2nd ed.). Georgia, USA: The Fairmont Press. p. 187. ISBN 0-88173-332-6.

[9]. https://www.irjet.net/archives/V4/i4/IRJE T-V4I4846.pdf

[10]. http://www.jetir.org/papers/JETIRC0062 33.pdf 